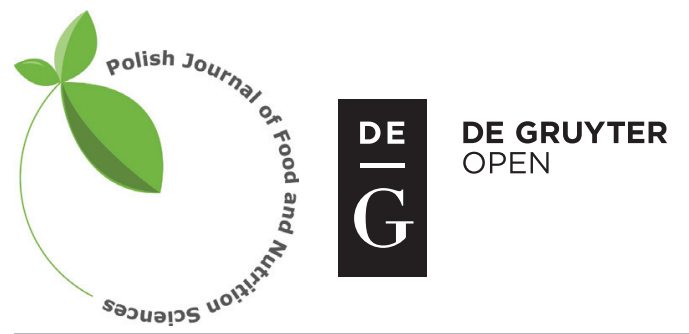

Pol. J. Food Nutr. Sci., 2017, Vol. 67, No. 4, pp. 317-325

DOI: $10.1515 /$ pjfns-2017-0008 http://journal.pan.olsztyn.pl

Original research article

Section: Food Chemistry

\title{
Polyphenol Profiles and Antioxidant Properties of Ethanol Extracts from Osmanthus Fragrans (Thunb.) Lour. Flowers
}

\author{
Hong-Ling Lit ${ }^{1,2}$, Zhi Chai ${ }^{1}$, Garry X. Shen ${ }^{3}$, Chun-Yang Li $^{1,2 *}$ \\ ${ }^{I}$ College of Food Science and Technology, Nanjing Agricultural University, Nanjing, China \\ ${ }^{2}$ Department of Functional Food and Bio-Active Compounds, Institute of Farm Product Processing, \\ Jiangsu Academy of Agricultural Sciences, No.50 Zhongling Street, Nanjing, Jiangsu, 210014, China \\ ${ }^{3}$ Departments of Internal Medicine and Human Nutritional Sciences, \\ University of Manitoba, Winnipeg, MB, R3E 3P4, Canada
}

Key words: ethanol extracts of Osmanthus fragrans flowers, antioxidant, polyphenol profiles, cultured endothelial cells

This study evaluated the antioxidant activity of ethanol extracts of Osmanthus fragrans (Thunb.) Lour. flowers (EOF) and identified phenolic compounds in EOF using liquid chromatography-mass spectrometry. Nine compounds, 3-O-caffeoylquinic acid, caffeic acid 4-O-glucoside, salidroside, 5-O-coumaroylquinic acid, 4-O-coumaroylquinic acid, acteoside, ligustroside, fucosterol and arjunolic acid were identified. To our knowledge, caffeic acid 4- $O$-glucoside, 5-O-coumaroylquinic acid and 4-O-coumaroylquinic acid have not been detected in EOF. In vitro antioxidant activity analysis demonstrated that EOF possessed strong DPPH and ABTS radicals scavenging activity with $\mathrm{EC}_{50}$ values at $0.26 \pm 0.06 \mathrm{mg} / \mathrm{mL}$ and $0.36 \pm 0.01 \mathrm{mg} / \mathrm{mL}, \mathrm{re}-$ spectively, and reducing power with $\mathrm{Ab}_{05}$ value at $13.04 \pm 0.16 \mu \mathrm{g} / \mathrm{mL}$. The value of oxygen radical absorbance capacity $(\mathrm{ORAC})$ was $333.23 \pm 13.39 \mu \mathrm{mol}$ Trolox/g. Antioxidant activity assay in human umbilical vein endothelial cells (HUVEC) showed that the activity of superoxide dismutase (SOD) was significantly improved and the reactive oxygen species (ROS) was removed effectively from cells when treated with EOF of $300 \sim 3000 \mu \mathrm{g} / \mathrm{L}$.

Abbreviations: TEAC: Trolox equivalent antioxidant capacity; ORAC: oxygen radical absorbance capacity; EOF: ethanol extracts of Osmanthus fragrans flowers; OF: Osmanthus fragranslour (Thunb.) Lour; HUVEC: human umbilical vein endothelial cells; SOD: superoxide dismutase; ROS: reactive oxygen species; ABTS: 2,2'-azinobis (3-ethylbenzothiazoline-6-sulfonic Acid Ammonium Salt); DPPH: 1-diphenyl-2-picryhydrazyl; LDH: lactic dehydrogenase; BCA: bicinchoninic acid; TNF- $\alpha$ : tumor necrosis factor- $\alpha$; TPC: total phenolic content; FRAP: ferric reducing antioxidant power.

\section{INTRODUCTION}

Osmanthus fragranslour (Thunb.) Lour. (OF), native to Asia and widely cultivated in China, Taiwan, Japan, Korea and other places in the world, belongs to the Oleaceae family [Omura et al., 2000]. OF flowers are valued for their delicate fruity-floral apricot aroma. They are especially valued as an additive for some cake, wine, tea and other beverages to increase or improve their taste in this country. OF has also been in use as a medicinal plant for thousands of years in China, and possesses a broad spectrum of biological effects, including anticancer, anti-inflammatory and antioxidant activities [Huang et al., 2015; Lee et al., 2011a]. The biological properties of OF have been considered due to phenolic compounds in various parts of the plant [Wang et al., 2009].

Previous studies described several functional compounds of OF, including verbascoside [Hung et al., 2012], salidroside [Ouyang et al., 2015], ligustroside [Liu et al., 2015], (+)-phillygenin, phillyrin, (-)-phillygenin [Lee et al.,

\footnotetext{
* Corresponding Author: Tel.: +86-25 8439-2191; Fax: +86-25 8439-1677;

E-mail: lichunyang968@126.com (Dr. Chun-Yang Li)
}

2011b], and pomolic acid [Yoo et al., 2013]. Ethanol extracts of OF flower (EOF) were shown to be characterized by a high content of total phenolics (TPC) and a strong antioxidant activity [Ouyang et al., 2015; Wu et al., 2009; Lee et al., 2007; Huang et al., 2015]. The phenolic extracts of OF exhibited evident augments in ferric reducing antioxidant power assay (FRAP) and radical scavenging ability in vitro [Wu et al., 2009; Lee et al., 2007; Zeng et al., 2014]. The extracts also inhibited lipid per-oxidation initiated by ferrous chloride in rat brain, liver, heart and kidney mitochondria [Lee et al., 2007], and the growth of $P$. gingivalis, especially in iron-limited culture medium, and markedly upregulated the expression of the cytoprotective enzyme and nucleoprotein Nrf2 [Huang et al., 2015].

The present study examined phenolic profiles and antioxidant properties of EOF. Liquid chromatography diode array detection and time of flight mass spectrometer (LC-DAD-TOF-ESI-MS2) were employed to analyze phenolic profiles. The antioxidant properties of phenolic compounds from OF flowers and their effects on the removal of ROS in cell-free and cytokines-stimulated endothelial cells (EC) were further assessed. 


\section{MATERIALS AND METHODS}

\section{Chemicals}

HPD100 macro porous resin was purchased from Cangzhou Bon Adsorber Technology Ltd. (Hebei province, China). RPMI-1640 medium, fetal bovine serum (FBS), and TNF- $\alpha$ were purchased from Gibco/Invitrogen (Shanghai, China). 2',7'-Dichlorodihydrofluorescein diacetate (DCFH-DA), ROS, BCA, and SOD assay kit and Radio Immunoprecipitation Assay (RIPA) lysis buffer were bought from Beyotine Technology Inc. (Nanjing, China). ABTS (2,2'-Azinobis (3-ethylbenzothiazoline-6-sulfonic Acid Ammonium Salt), DPPH (1,1-diphenyl-2-picrylhydrazyl), Trolox (6-hydroxy-2,5,7,8-tetramethylchroman carboxylic acid), Folin-Ciocalteu phenol reagent, and gallic acid were purchased from Sigma-Aldrich Inc. (St. Louis, MO, USA). Ethanol (analytical grade) and methanol (HPLC grade) were purchased from Fisher Scientific (Fair Lawn, NJ, USA). Acetic acid (HPLC grade) was obtained from J.T. Baker (Phillipsburg, NJ, USA). Water used to prepare solutions or mobile phase was purified using Milli-Q-Integral System (Merk Millipore, MA, USA). Seed cells of HUVEC were purchased from the CELL RESEARCH Biological Technology Ltd. (Shanghai, China).

\section{Plant materials and extraction}

Dried Osmanthus fragrans var. thunbergii flowers was obtained from 'Fangzhi Lin' ecological garden (Nanjing, China). The dried material (100 g) was extracted with ethanolwater $(1000 \mathrm{~mL}, 70: 30, \mathrm{v} / \mathrm{v})$ using an Ultrasonic sonicator (KQ5200E, Kunshan, China) at $40 \mathrm{kHz}$ and $100 \mathrm{~W}$ for $2 \mathrm{~h}$ at room temperature. The extract was filtered through a $0.45 \mu \mathrm{m}$ nylon Acrodisc 25 filter (Gelman, Ann Arbor, MI, USA).

The filtrates were concentrated with a rotary evaporator (RE-52A, Shanghai, China) and frozen to dry with a vacuum frozen dryer machine (EYELA FDU-1200, Tokyo, Japan). The dried extracts (about $10 \mathrm{~g}$ ) were dissolved with ultra-pure water and adsorbed by HPD100 macroporous resin placed in the plexiglass column (inside diameter $15 \mathrm{~mm}$, outside diameter $20 \mathrm{~mm}$, height $350 \mathrm{~mm}$ ), then purged with ultrapure water to remove proteins and sugars and eluted with ethanol-water $(1000 \mathrm{~mL}, 50: 50, \mathrm{v} / \mathrm{v})$ again. The elute $(20 \mathrm{~mL})$ was used to measure TPC, phenolic compositions, and antioxidant properties. The rest was concentrated with a rotary evaporator and frozen to dried again. The powder was stored at $-20^{\circ} \mathrm{C}$ until used.

\section{Mass spectrometry}

LC-DAD-TOF-ESI-MS² consists of a liquid chromatograph (LC) with a diode array detector (DAD) coupled to time of flight mass spectrometer (TOF) [Agilent $1100 \mathrm{LC} / \mathrm{MS}$ (SL), USA]. A $250 \mathrm{~mm} \times 4.6 \mathrm{~mm}, 5 \mu \mathrm{m}$, Symmetry C18 column (Waters Corp., Milford, MA, USA) and sentry guard column were used at a flow rate of $0.6 \mathrm{~mL} / \mathrm{min}$. The column oven temperature was set at $35^{\circ} \mathrm{C}$. The mobile phase consisted of a combination of A (water) and B (methanol), both containing $1 \%$ acetic acid. The following gradient elution scheme was expressed by B (v/v): 0-5 min, 5\%-20\%; 5-15 min, 20\%-25\%; $15-25 \mathrm{~min}, 25 \%-35 \%$; 25-30 min, 35\%-38\%; 30-40 min, 38\%$42 \%$; 40-50 min, 42\%-48\%; 50-55 min, 48\%-50\%; 55-65 min,
50\%-60\%; 65-75 min, 60\%-75\%; 75-80 $\min , \quad 75 \%-80 \%$; 80-85 min, $80 \%-83 \%$; 85-90 $\mathrm{min}, 83 \%-85 \%$; 90-95 min, $85 \%-20 \%$ and $95-100 \mathrm{~min}, 20 \%-5 \%$. The re-equilibration time was $10 \mathrm{~min}$. The injection volume was $10 \mu \mathrm{L}$. The DAD was set at $280 \mathrm{~nm}$ for flight time monitoring of the peak intensity and full spectra $(190-650 \mathrm{~nm})$ were continuously recorded for plant component identification. Mass spectra were simultaneously acquired using electro spray ionization in the negative ion modes at fragmentation voltages $(3.5 \mathrm{KV})$ over the range of $\mathrm{m} / \mathrm{z} 100-1000$ and $\mathrm{MS}^{2}$ data were collected in the total ion counting model.

\section{Antioxidant activity in vitro}

\section{Total phenolics content (TPC)}

TPC of EOF was determined with using Folin-Ciocalteu'a phenol reagent [Spanos \& Wrolstad, 1990]. Extract solution $(1 \mathrm{~mL})$ was mixed with $1 \mathrm{~mL}$ of $2 \mathrm{~N}$ Folin-Ciocalteu reagent for $6 \mathrm{~min}$. After the addition of $3 \mathrm{~mL}$ of $7.5 \%$ $\mathrm{Na}_{2} \mathrm{CO}_{3}$ solution, the volume was made up to $10 \mathrm{~mL}$ with ethanol-water $(50: 50, \mathrm{v} / \mathrm{v})$ solvents, followed by an incubation for $2 \mathrm{~h}$ at room temperature. Absorbance of the mixture was measured at $765 \mathrm{~nm}$ using UV-5500/Ultraviolet visible spectrophotometer (Shanghai, China). TPC was calculated from the calibration curve of gallic acid $(y=0.031 \mathrm{x}-0.007$, $r=0.9995)$ and expressed as milligram of gallic acid equivalent per gram of OF flowers (dry weight).

\section{ABTS radical scavenging activity}

The ABTS radical-scavenging activity was measured as performed by Re et al. [1999] with modifications. All measurements were performed as follows: $100 \mu \mathrm{L}$ of EOF in various concentrations $(0.002-1.0 \mathrm{mg} / \mathrm{mL})$ were mixed with $3 \mathrm{~mL}$ of ABTS radical cation solution. Then the mixture was vibrated for $20 \mathrm{~s}$, followed by standing for $6 \mathrm{~min}$. The absorbance was measured at $734 \mathrm{~nm}$ using the same volume of ethanol-water $(50: 50, \mathrm{v} / \mathrm{v})$ solvents as the blank sample. The ABTS radical cation solution was the control sample. Trolox was used as an antioxidant standard. Trolox equivalent antioxidant capacity (TEAC) was expressed as millimole Trolox equivalents per gram OF flowers (dry weight) ( $\mu \mathrm{mol}$ Trolox $/ \mathrm{g}$ ).

$$
\text { ABTS radical scavenging activity }(\%)=\frac{1-\left(\mathrm{A}_{\text {sample }}-\mathrm{A}_{\text {blank }}\right)}{\mathrm{A}_{\text {Control }}} \times 100
$$

The concentration of extract providing $50 \%$ of radical scavenging $\left(\mathrm{EC}_{50}\right)$ was calculated from the plot of ABTS radical scavenging activity against sample concentration by non-linear regression analysis.

\section{DPPH radical scavenging activity}

This DPPH assay was investigated by the modified method of Hatano et al. [1989]. In brief, $2 \mathrm{~mL}$ EOF of various concentrations $(0.002-1.0 \mathrm{mg} / \mathrm{mL})$ and $1 \mathrm{mmol} / \mathrm{L}$ DPPH solution $(1.0 \mathrm{~mL})$ were well mixed and left to stand in the dark at room temperature for $30 \mathrm{~min}$. The absorbance was measured at $517 \mathrm{~nm}$ and the sample in ethanol was used as the blank, while DPPH radical in ethanol solution was used as a control. 
Then, the DPPH radical scavenging activity was calculated according to the following equation:

$$
\text { DPPH radical scavenging activity }(\%)=\frac{1-\left(\mathrm{A}_{\text {sample }}-\mathrm{A}_{\text {blank }}\right)}{\mathrm{A}_{\text {Control }}} \times 100
$$

The concentration of extract providing $50 \%$ of radical scavenging $\left(\mathrm{EC}_{50}\right)$ was calculated from the plot of DPPH radical scavenging activity against sample concentration by non-linear regression analysis.

\section{Reducing power}

The reducing power of EOF was determined according to the method of Oyaizu et al. [1986] with minor modifications. One $\mathrm{mL}$ of EOF of various concentrations (0.002-1.0 $\mathrm{mg} / \mathrm{mL}$ ) was mixed with $2.5 \mathrm{~mL}$ of phosphate-buffered saline (PBS) $(2.0 \mathrm{~mol} / \mathrm{L}, \mathrm{pH}$ 6.6) and $2.5 \mathrm{~mL}$ of potassium ferricyanide $(1.0 \%)$. The mixture was incubated at $50^{\circ} \mathrm{C}$ for $20 \mathrm{~min}$. Afterwards, $1.0 \mathrm{~mL}$ of trichloroacetic acid (10\%) had been added to the mixture, the mixture was centrifuged at $2,500 \times \mathrm{g}$ for $10 \mathrm{~min}$. Then, $2.5 \mathrm{~mL}$ of the supernatant was mixed with $2.5 \mathrm{~mL}$ of distilled water and $0.5 \mathrm{~mL}$ of $0.1 \%$ ferric chloride. Without sample addition was the control sample. The absorbance of the final mixture was measured at $700 \mathrm{~nm}$ using the UV-5500 spectrophotometer (Shanghai, China). The reducing power was calculated using the following formula:

$$
\text { Reducing power }=\mathrm{A}_{\text {sample }}-\mathrm{A}_{\text {Control }}
$$

The extract concentration providing 0.5 of absorbance $\left(\mathrm{Ab}_{0.5}\right)$ was calculated from the graph of absorbance at $700 \mathrm{~nm}$ against extract concentration by linear regression analysis.

\section{ORAC assay}

The ORAC assay was carried out as described by Mertz et al. [2009] with minor modifications. TriStar LB 941 microplate reader (Berthold Technologies, Germany) was used with fluorescence filters for an excitation wavelength of $485 \mathrm{~nm}$ and an emission wavelength of $535 \mathrm{~nm}$. The final assay solution contained $100 \mu \mathrm{L}$ of $40 \mu \mathrm{mol} / \mathrm{L}$ fluorescein working solution, $50 \mu \mathrm{L}$ of phosphate buffer (blank), Trolox standard or EOF. The mixture was pre-incubated at $37^{\circ} \mathrm{C}$ for $10 \mathrm{~min}$ before $50 \mu \mathrm{L}$ of the prepared AAPH $(60 \mathrm{mmol} / \mathrm{L})$ was added. The fluorescence of the mixture solution was recorded every minute for a total of $50 \mathrm{~min}$. The ORAC values were expressed as micromoles of Trolox equivalents per gram of OF flowers (dry weight) ( $\mu \mathrm{mol}$ Trolox/g).

\section{Antioxidant activity of EOF in HUVEC}

\section{Endothelial cell culture and treatment}

The 5th to 6th passage cells were used for all experiments at $80 \% \sim 90 \%$ confluence. The cells were quiescenced in a reduced serum medium for $4 \mathrm{~h}$ prior to experiment. In a separate set of experiments, the cells were treated with EOF of $30 \mu \mathrm{g} / \mathrm{L}$ (test 1), $300 \mu \mathrm{g} / \mathrm{L}$ (test 2) and $3000 \mu \mathrm{g} / \mathrm{L}$ (test 3), for $18 \mathrm{~h}$, followed by TNF- $\alpha(10 \mu \mathrm{g} / \mathrm{L})$ stimulation for $6 \mathrm{~h}$. Only RPMI-1640 was used as control 1. RPMI-1640 supplemented with TNF- $\alpha$ $(10 \mu \mathrm{g} / \mathrm{L})$ was control 2.

\section{Determination of ROS contents in endothelial cells}

After growth medium was removed, the cells were washed using PBS. Twenty-five $\mu$ mol of DCFH-DA were dissolved in the treatment medium without FBS, and incubated at $37^{\circ} \mathrm{C}$ and $5 \% \mathrm{CO}_{2}$ for $20 \mathrm{~min}$. The cells were washed with PBS three times. After all these procedures, fluorescence intensity $\left(\lambda_{\mathrm{ex}}=485 \mathrm{~nm}, \lambda_{\mathrm{em}}=538 \mathrm{~nm}\right)$ was monitored using a microplate reader and detected by Ultra View VOX (PerkinElmer Company, USA) at the same time. Cells were observed at $10 \%$ of the laser intensity and photographed. The content of ROS was expressed by fluorescence intensity.

\section{Activity of SOD in cells}

First, cells were centrifuged at $2,000 \times \mathrm{g}$ for $10 \mathrm{~min}$, growth medium was discarded, washed by PBS, and then centrifuged at $2,000 \times \mathrm{g}$ for $10 \mathrm{~min}$ again, supernatants were removed. Finally, $80 \mu \mathrm{L}$ of the RIPA lysis buffer were added to cells and the mixture was centrifuged at $10,000 \times \mathrm{g}$ for $10 \mathrm{~min}$, supernatants were collected for the measurement of the activity of SOD, which was determined using BCA and SOD assay kit according to the instructions.

\section{Statistical analysis}

All data were presented in mean value \pm standard deviation (SD). The data were analyzed by one-way ANOVA using the SAS 8.2 statistical software. Differences were considered significant at $p<0.05$. The fitted curve and value of $\mathrm{EC}_{50}$ was obtained through the Globe model (non-linear regression model) from GraphPad prism 5.0 software [Khan et al., 2012; Kis et al., 2009]. The equation was as follows:

$$
\mathrm{Y}=\text { Bottom }+\frac{\text { Top }- \text { Bottom }}{1+10^{(\text {LogEC } 50-X) \times \text { HillSlope })}}
$$

where: Top and Bottom were plateaus in the units of the $\mathrm{Y}$ axis. $\mathrm{EC}_{50}$ was the concentration of agonist that gives a response half way between Bottom and Top. Hill slope describes the steepness of the family of curves. A HillSlope of 1.0 is standard, and you should consider constraining the Hill Slope to a constant value of 1.0. A Hill slope greater than 1.0 is steeper, and a Hill slope less than 1.0 is shallower.

\section{RESULTS AND DISCUSSION}

\section{Polyphenol profiles of EOF analysis}

A chromatogram of EOF was shown in Figure 1 and the corresponding chromatographic peaks of the nine compounds were labeled as 1-9. The retention times (TR), molecular ions $\left([\mathrm{M}-\mathrm{H}]^{-}\right)$and major fragment ions of the peaks were listed in Table 1. Proposed cleavage positions of compound salidroside, acteoside, ligustroside, fucosterol, and arjunolic acid were displayed in Figure 2.

The peak 1, eluted at $3.7 \mathrm{~min}$, had a NI quasi-molecule ion at $\mathrm{m} / \mathrm{z}$ of 352.8 (Table 1). The unknown compound lost inner glucose residue (162 amu) [Ma et al., 2000] and yielded the $\mathrm{Y}_{0}^{*}$ ion at $\mathrm{m} / \mathrm{z}$ 191.2. Other important fragment-ion peaks 


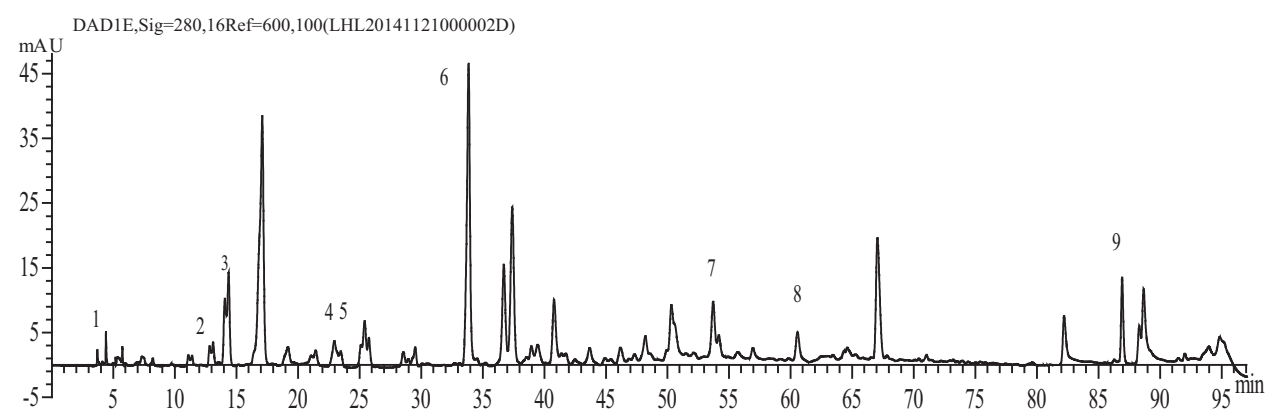

FIGURE 1. Chromatogram of ethanol extract of Osmanthus fragrans (Thunb.) Lour. flowers at $280 \mathrm{~nm}$.

at $\mathrm{m} / \mathrm{z} 179.1, \mathrm{~m} / \mathrm{z} 173.1$ and $\mathrm{m} / \mathrm{z} 135.2$ were consistent with that of 3-O-caffeoylquinic acid [Lin \& Harnly, 2010]. 3-O-Caffeoylquinic acid was isolated and identified from the ethyl acetate fraction of the alcohol extract of the OF [Yin et al., 2013].

The peak 2 was eluted at $12.8 \mathrm{~min}$. It showed that the peak of the highest mass was m/z $341.0[\mathrm{M}-\mathrm{H}]^{-}$. The loss of a glucose moiety (162 amu) from it produced $\mathrm{Y}_{0}^{*}$ ion at $\mathrm{m} / \mathrm{z} 178.7$, which further produced a fragment ion at $\mathrm{m} / \mathrm{z} 160.8$ by $\mathrm{H}_{2} \mathrm{O}$ group (18 amu) dissociation. These diagnostic fragments were the same with that of caffeic acid 4-O-glucoside [Lin \& Harnly, 2010].

The peak 3 was eluted at $14.0 \mathrm{~min}$. It showed that the highest $\mathrm{m} / \mathrm{z}$ value was 599.1 in the negative mode. The molecular complexes $\left([2 \mathrm{M}-\mathrm{H}]^{-}\right)$can be generated when adducts were with acid molecules [Barnes et al., 1994; de Rijke et al., 2003; Tian et al., 2002]. The molecule ion was detected at $\mathrm{m} / \mathrm{z} 298.9\left([(\mathrm{M}-\mathrm{H}) / 2]^{-}\right)$. Then the molecular ion formed $\mathrm{m} / \mathrm{z} 178.8$ through a loss of a $120 \mathrm{amu}$ (Figure 2). These fragments were conformed to that of salidroside and identified in the extract from pulps of EOF [Ouyang et al., 2015].

The peaks 4 and 5 were eluted at $22.9 \mathrm{~min}$ and $23.2 \mathrm{~min}$, respectively. The molecular ion $[\mathrm{M}-\mathrm{H}]^{-}$of the two peaks ( $\mathrm{m} / \mathrm{z}$ value) is 337.0. The $\mathrm{Y}_{0}^{*}$ ion at $\mathrm{m} / \mathrm{z} 190.8$ was formed as a result of a $p$-Co (146.2 amu) loss from the quasi-molecular ion of the peak 4. A $p$-Co and $\mathrm{H}_{2} \mathrm{O}$ were lost from the quasi-molecular ion of peak 5 and yielded the $\mathrm{Y}_{0}^{*}$ ion at $\mathrm{m} / \mathrm{z}$ 172.8. These fragments matched that of 5-O-coumaroylquinic acid and 4-O-coumaroylquinic acid, respectively [Clifford et al., 2003].

The peak 6 was eluted at $33.8 \mathrm{~min}$, with a molecule ion at $\mathrm{m} / \mathrm{z}$ 623.4. The $\mathrm{Y}_{0}^{*}$ fragment at $\mathrm{m} / \mathrm{z}$ 461.2, a 162 amu difference between this ion and the precursor $[\mathrm{M}-\mathrm{H}]^{-}$ion corresponds to the loss of a glucose residue (Figure 2). These fragments were consistent with that of acteoside [Lin \& Harnly, 2010], which was isolated from the $\mathrm{CHCl}_{3}$ sub-extract of OF [Hung et al., 2012].

The peak 7 had a retention time of $53.7 \mathrm{~min}$, with molecular ions at $\mathrm{m} / \mathrm{z} 523.1$ and yielded the $\mathrm{Y}_{0}^{*}$ fragment at $\mathrm{m} / \mathrm{z} 361.0$ after loss of the inner glucose residue (162 amu). Cleavage at the glycosidic $O$-linkages with a concomitant $\mathrm{H}$-rearrangement leads to the elimination of monosaccharide residues (Figure 2). And other diagnostic fragmention at $\mathrm{m} / \mathrm{z} 291.0$ and 259.0 were confirmed to ligustroside. The chemical compound has been identified from OF [Hung et al., 2012; Liu et al., 2015].

The peak 8, eluted at $60.6 \mathrm{~min}$, had a molecular ion at $\mathrm{m} / \mathrm{z} 411.1$. $\mathrm{Y}_{0}^{*}$ ion at $\mathrm{m} / \mathrm{z} 248.9$ was obtained by the second-order mass spectrum. The cleavage position was shown in Figure 2. And other important fragments such as $\mathrm{m} / \mathrm{z} 493.0$, 216.8 and 575.0, were the same with that of fucosterol. Fucosterol was isolated and identified from the ethyl acetate fraction of OF [Lee et al., 2011a].

The peak 9, eluted at 86.9 min, had a NI molecular ion at $\mathrm{m} / \mathrm{z}$ 487.4. The loss of a water moiety (18 amu) from

TABLE 1. Peaks assignments of the ethanol extract of Osmanthus fragrans (Thunb.) Lour. (EOF) flowers.

\begin{tabular}{|c|c|c|c|c|c|}
\hline $\begin{array}{l}\text { Peaks. } \\
\text { no. }\end{array}$ & $\mathrm{TR}(\min )$ & {$[\mathrm{M}-\mathrm{H}]^{-}(m / z)$} & $\mathrm{Y}_{0}^{*}(m / z)$ & Diagnostic fragments $(m / z)$ & Identification \\
\hline 1 & 3.7 & 352.8 & 191.2[M-H-161.6] & 179.1(a)/173.1(b)/135.2(c) & 3-O-Caffeoylquinic acid \\
\hline 2 & 12.8 & 341.0 & 178.7[M-H-162.3] & $160.8(a) / 134.9(b)$ & Caffeic acid 4-glucoside \\
\hline 3 & 14.1 & 599.1 & $298.9[(\mathrm{M}-\mathrm{H}) / 2]^{-}$ & $178.8(\mathrm{a}) / 118.8(\mathrm{~b})$ & Salidroside \\
\hline 4 & 22.9 & 337.0 & $190.8[\mathrm{M}-\mathrm{H}-P \mathrm{Co}]^{-}$ & $162.8(\mathrm{a}) / 172.8(\mathrm{~b})$ & 5-O-Coumaroylquinic acid \\
\hline 5 & 23.2 & 337.0 & $172.8\left[\mathrm{M}-\mathrm{H}-P \mathrm{Co}-\mathrm{H}_{2} \mathrm{O}\right]^{-}$ & 190.8(a)/162.8(b) & 4-O-Coumaroylquinic acid \\
\hline 6 & 33.8 & 623.4 & 461.2[M-H-162.2] ${ }^{-}$ & $315.0(a) / 179.1(b) / 161.0(c)$ & Acteoside \\
\hline 7 & 53.7 & 523.1 & 361.0[M-H-162.1] ${ }^{-}$ & $291.0(\mathrm{a}) / 259.0(\mathrm{~b})$ & Ligustroside \\
\hline 8 & 60.6 & 411.1 & $248.9[\mathrm{M}-\mathrm{H}-162.2]^{-}$ & 493.0(a)/216.8(b)/575.0(c) & Fucosterol \\
\hline 9 & 86.9 & 487.4 & $469.3\left[\mathrm{M}-\mathrm{H}-\mathrm{H}_{2} \mathrm{O}\right]^{-}$ & $425.7(\mathrm{a}) / 443.7(\mathrm{~b}) / 371.5(\mathrm{c})$ & Arjunolic acid \\
\hline
\end{tabular}

Note: $a, b, c$ and d indicate the size of the ion abundance, respectively. $a>b>c>d$. 


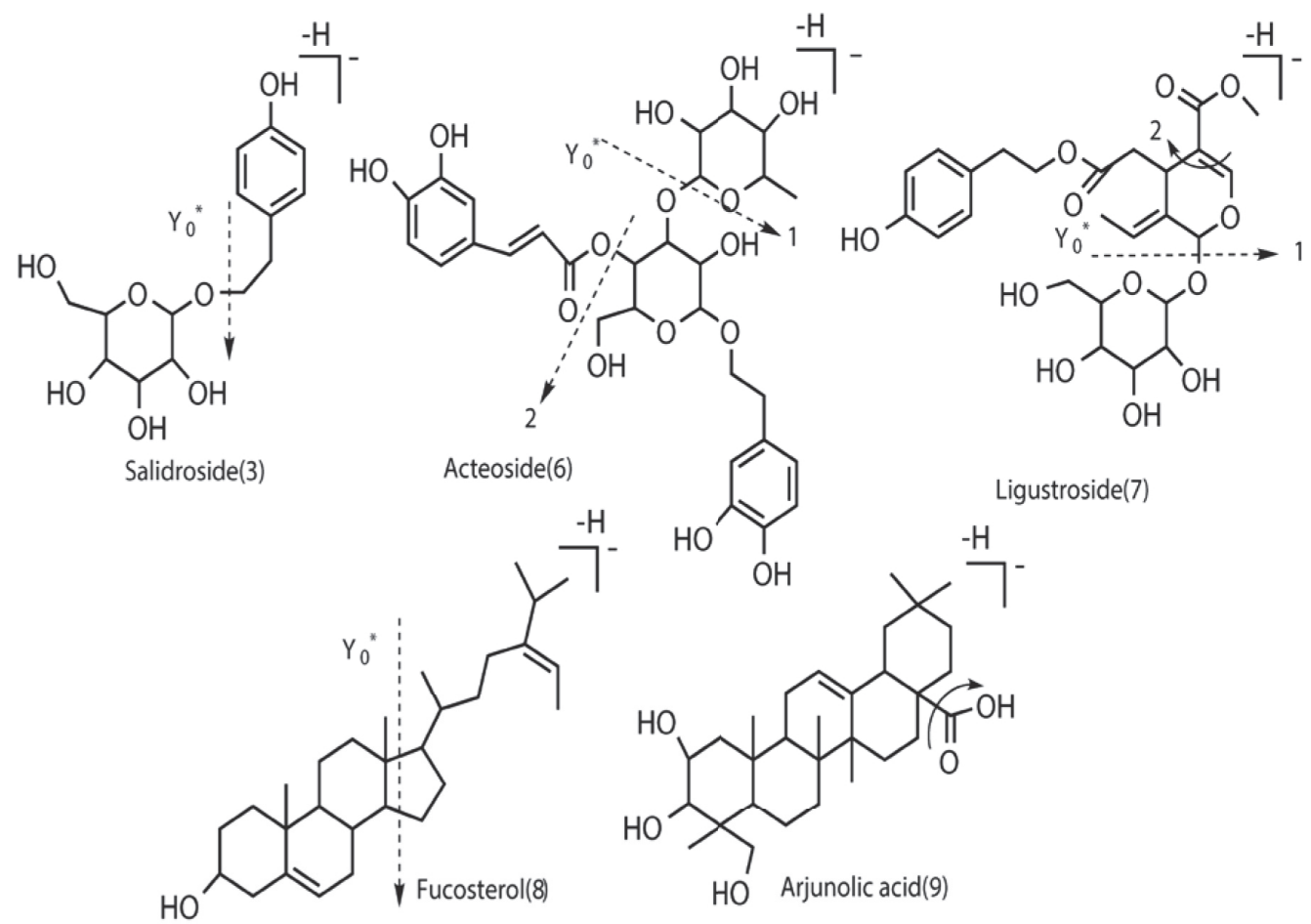

FIGURE 2. Proposed fragmentation positions of EOF compounds.

the molecular ion produced $\mathrm{Y}_{0}^{*}$ ion at $\mathrm{m} / \mathrm{z} 469.3$, which further produced a fragment ion at $\mathrm{m} / \mathrm{z} 425.7$ by the $\mathrm{CO}_{2}$ group (44 amu) dissociation (Figure 2). These diagnostic fragments were the same with that of arjunolic acid. Arjunolic acid was isolated and identified from the ethyl acetate fraction of alcohol extract of the OF [Yin et al., 2013].

The 9 phenolic compounds were identified from OF extracts using ethanol-water $(70: 30, \mathrm{v} / \mathrm{v})$ as solvents. 3-O-Caffeoylquinic acid, salidroside (peak 3), acteoside (peak 6), ligustroside (peak 7), fucosterol (peak 8), and arjunolic acid (peak 9) have been reported from anhydrous alcohol extracts of OF. Three compounds: caffeic acid 4-O-glucoside (peak 2), 5-O-coumaroylquinic acid (peak 4), and 4- $O$-coumaroylquinic acid (peak 5) have not been reported to be associated with EOF. So further studies on polyphenol profiles of ethanol-water extracts from OF are indicated.

\section{Total phenolics content of OF flowers}

TPC of OF flowers was $18.06 \mathrm{mg} / \mathrm{g}$ (dry weight) (Table 2). Li et al. [2014] obtained a similar result $-16.0 \mathrm{mg} / \mathrm{g}$. In turn, Lee et al. [2007] and Zeng et al. [2014] reported higher contents of total phenolics in OF flowers - $193 \mu \mathrm{g} / \mathrm{mg}$ d.w. and $47.45 \mathrm{mg} / \mathrm{g}$, respectively. The value determined in the present study shows that the content of total phenolic compounds in OF flowers is higher than that estimated for commonly consumed legumes and cereals [Weidner et al., 1999; Orak et al., 2016] and comparable to TPC noted for many edible flowers and fruits of herbs [Zeng et al., 2014; Li et al., 2014; Arfan et al., 2007].

\section{Antioxidant properties of EOF in vitro}

The reducing power assay is an electron transfer method based on the reduction of the $\mathrm{Fe}^{3+} /$ ferricyanide complex to its ferrous form in the presence of antioxidants [Oyaizu et al., 1986]. Reducing power against sample concentration was fitted according to the linear regression. With rising concentration, the reducing power of Trolox and EOF were also ascending. The reducing power of EOF was slightly higher than that of Trolox under the same concentration, and close to 3.0 at the concentration of $1 \mathrm{mg} / \mathrm{mL}$ (Figure 3). The $\mathrm{Ab}_{0.5}$ of EOF and Trolox were 0.13 and $0.15 \mathrm{mg} / \mathrm{mL}$, respectively (Table 2). Lee et al. [2007] obtained a lower value for the ethanolic extract of Osmanthus fragrans flowers - $7.74 \mu \mathrm{g} / \mathrm{mL}$ - using FRAP assay, in which the ferric tripyridyl triazine (Fe(III)TPTZ) complex is reduced to the ferrous form. Whereas, as in our study, the difference between values for Trolox and EOF was slight.

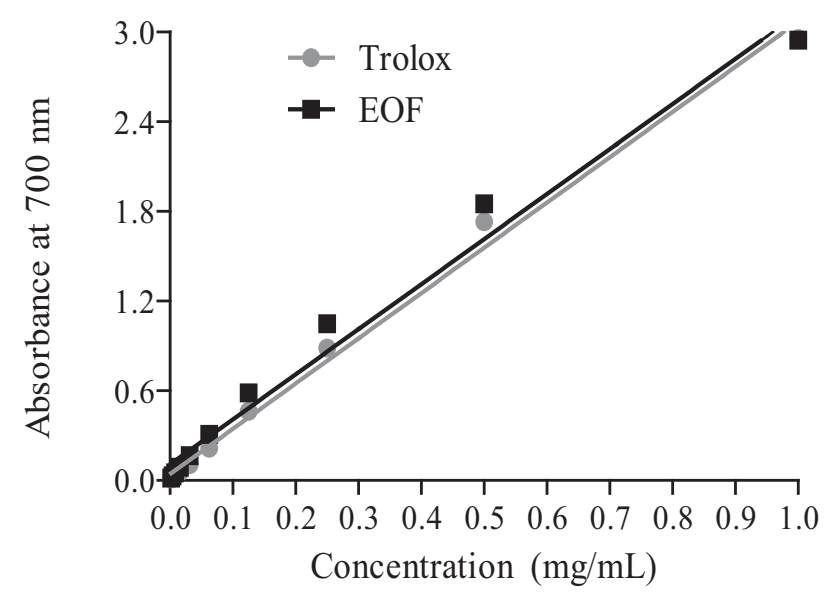

FIGURE 3. The effects of concentration of EOF and Trolox on the reducing power.

Each value is mean \pm standard derivation $(\mathrm{SD})$ of three replicate analyses. 
TABLE 2. Antioxidant properties of EOF.

\begin{tabular}{l|c|c|c|c|c|c}
\hline & $\begin{array}{c}\mathrm{DPPH} \\
\mathrm{EC}_{50}(\mathrm{mg} / \mathrm{mL})\end{array}$ & $\begin{array}{c}\mathrm{ABTS} \\
\mathrm{EC}_{50}(\mathrm{mg} / \mathrm{mL})\end{array}$ & $\begin{array}{c}\text { Reducing Power } \\
\mathrm{Ab}_{50}(\mathrm{mg} / \mathrm{mL})\end{array}$ & $\begin{array}{c}\text { ORAC } \\
(\mu \mathrm{mol} \text { Trolox } / \mathrm{g})\end{array}$ & $\begin{array}{c}\text { TEAC } \\
(\mu \mathrm{mol} \mathrm{Trolox} / \mathrm{g})\end{array}$ & $\begin{array}{c}\text { TPC } \\
(\mathrm{mg} / \mathrm{g})\end{array}$ \\
\hline EOF & $0.26 \pm 0.06^{\mathrm{a}}$ & $0.36 \pm 0.01^{\mathrm{a}}$ & $0.13 \pm 0.02^{\mathrm{b}}$ & $333.23 \pm 18.39$ & $285.20 \pm 2.15$ & $18.06 \pm 0.24$ \\
Trolox & $0.01 \pm 0.00^{\mathrm{b}}$ & $0.25 \pm 0.01^{\mathrm{b}}$ & $0.15 \pm 0.01^{\mathrm{a}}$ & - & - & - \\
\hline
\end{tabular}

Note: The ABTS, DPPH and Reducing power results are expressed per $\mathrm{mL}$ of extract and ORAC, TEAC and TPC - per g of Osmanthus Fragrans (Thunb.) Lour. flowers (dry weight). Values are mean $\pm \mathrm{SD}(\mathrm{n}=3)$. ${ }^{\mathrm{a}-\mathrm{b}}$ Values in each group are significantly different $(p<0.05)$.

The $\mathrm{EC}_{50}$ of DPPH and ABTS assays of EOF was higher than the result obtained for Trolox (Table 2). The DPPH $\mathrm{EC}_{50}$ of the ethanolic and acetonic extracts of OF flowers was determined by Lee et al. [2007] and Wu et al. [2009], respectively. The reported values $(9.99 \mu \mathrm{g} / \mathrm{mL}$ and $16.90 \mu \mathrm{g} / \mathrm{mL})$ were lower than that in the present study. The reason partly could be the use of various extraction solvents and differences in results expression. In turn, Wu et al. [2009] estimated $\mathrm{EC}_{50}$ of OF acetonic extract using ABTS assay and expressed it as $\mathrm{mg}$ Trolox equivalent/g of extract (516.3 mg Trolox/g). $\mathrm{EC}_{50}$ of Trolox and EOF from Table 2 calculated in this way provided a comparable value.

The ORAC assay is a next method used to evaluate the antioxidant capacity of food ingredients and products. Oxygen radical absorbance capacity of OF flowers was shown in Table 2. Literature provides no data for ORAC of OF, but the obtained value $-333.23 \mu \mathrm{mol}$ Trolox/g flowers (dry weight) - was comparable to results noted for some edible flowers used as herbs or food ingredients [Xiong et al., 2014].

\section{Antioxidant activities of EOF in HUVEC}

\section{Removal of ROS}

The fluorescence intensity of control 2 was significantly higher than that of control $1(p<0.001)$, which showed that TNF- $\alpha$-induced cells produced more ROS than normal cells

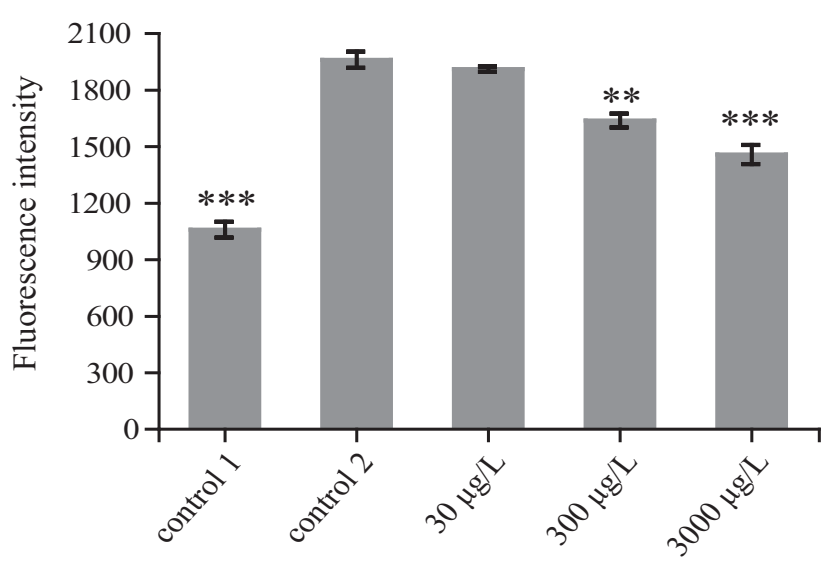

Different concentration of EOF

FIGURE 4. The effect of concentration of EOF on the content of ROS. HUVEC were treated with EOF of $30 \mu \mathrm{g} / \mathrm{L}, 300 \mu \mathrm{g} / \mathrm{L}$ and $3000 \mu \mathrm{g} / \mathrm{L}$ for $18 \mathrm{~h}$, followed by TNF- $\alpha(10 \mu \mathrm{g} / \mathrm{L})$ stimulation for $6 \mathrm{~h}$. Only treated with RPMI-1640 was control 1. RPMI- 1640 and TNF- $\alpha(10 \mu \mathrm{g} / \mathrm{L})$ was control 2. Each value is mean $\pm \mathrm{SD}$ of three replicate analyses. ${ }^{*}{ }^{*},{ }^{*}, * * *: p<0.05$, $p<0.01$ or $p<0.001$ versus TNF- $\alpha$ alone.
(Figure 4). This result was consistent with the previous studies [Hwa et al., 2011; Kim et al., 2005]. The fluorescent intensity was not significantly different from that of control 2 when $30 \mu \mathrm{g} / \mathrm{L}$ of EOF was used, which suggested that the removal effect of ROS was not distinct. The fluorescence intensities were significantly lower than that of control $2(p<0.01)$, which indicated that ROS was removed effectively at the concentrations of $300 \mu \mathrm{g} / \mathrm{L}$ and $3000 \mu \mathrm{g} / \mathrm{L}$ of EOF (Figure 4). ROS can trigger cells apoptosis, endothelial dysfunction, sclerosis, cancer, aging and inflammation etc. [Lenz et al., 2008; Calhoun et al., 2008]. Thus, EOF is potentially beneficial to individuals with those diseases.

\section{SOD activity in EC}

The activity of SOD in control 2 was significantly lower than that in control $1(P<0.001)$, indicating that the activity of SOD in cytosol was inhibited in TNF- $\alpha$-treated cells. When the concentration of EOF was $30 \mu \mathrm{g} / \mathrm{L}$, the activity of SOD was comparable to that of control 2, which indicated that there was no effect on the activity of SOD in the cells stimulated with TNF- $\alpha$. The activity of SOD in HUVEC treated with $300 \mu \mathrm{g} / \mathrm{L}$ or $3000 \mu \mathrm{g} / \mathrm{L}$ of EOF was significantly higher than that of control $2(P<0.01)$, which suggests that the activity of SOD was enhanced in cells exposed to high concentrations of EOF (Figure 5). The results were in accordance with Huang et al [2015] showing that the ethanol extract

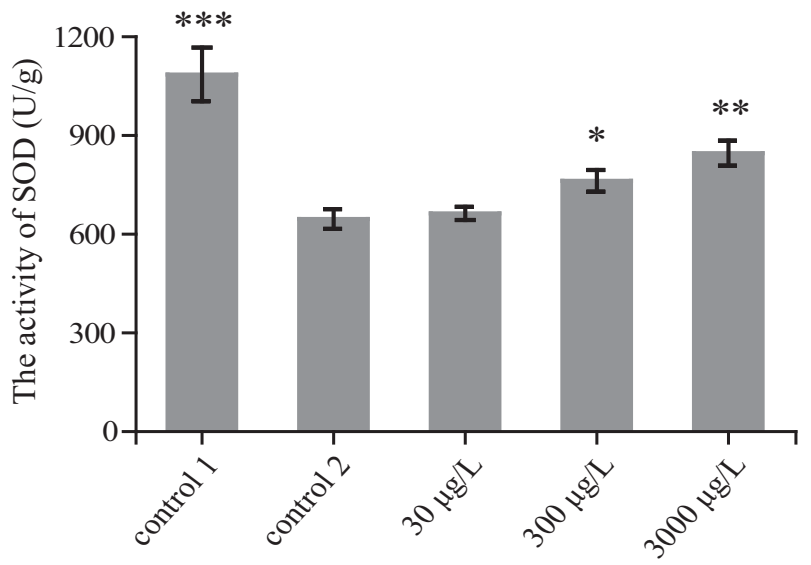

Different concentration of EOF

FIGURE 5. The effect of different concentration of EOF on the activity of SOD.

HUVEC were treated with EOF of $30 \mu \mathrm{g} / \mathrm{L}, 300 \mu \mathrm{g} / \mathrm{L}$ and $3000 \mu \mathrm{g} / \mathrm{L}$ for $18 \mathrm{~h}$, followed by TNF- $\alpha(10 \mu \mathrm{g} / \mathrm{L})$ stimulation for $6 \mathrm{~h}$. Only treated with RPMI-1640 was control 1. RPMI-1640 and TNF- $\alpha(10 \mu \mathrm{g} / \mathrm{L})$ was control 2. Each value is mean \pm standard derivation (SD) of three replicate analyses. *, **, ***: $p<0.05, p<0.01$ or $p<0.001$ versus TNF- $\alpha$ alone. 


\section{Control 1}

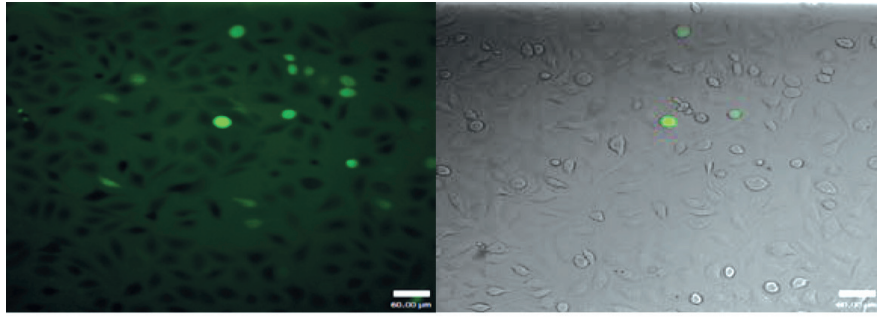

Control 2

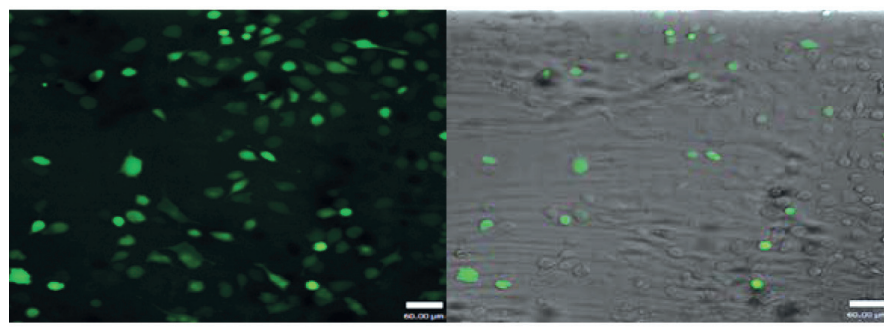

Test 1

$30 \mu \mathrm{g} / \mathrm{L}$

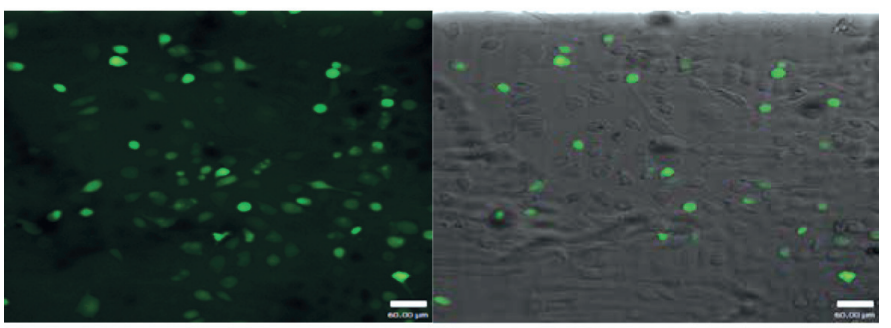

Test 2

$300 \mu \mathrm{g} / \mathrm{L}$

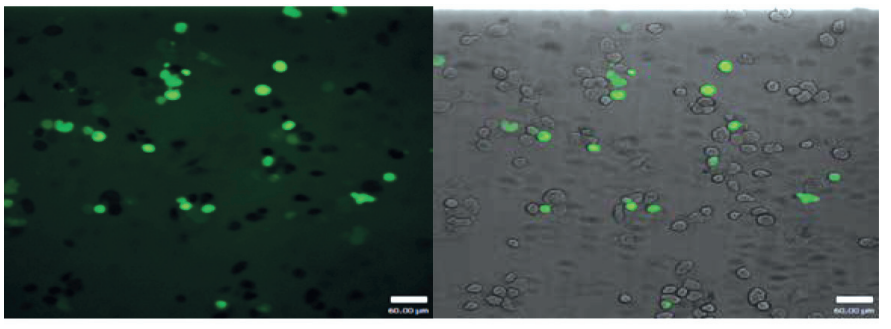

Test 3

$3000 \mu \mathrm{g} / \mathrm{L}$

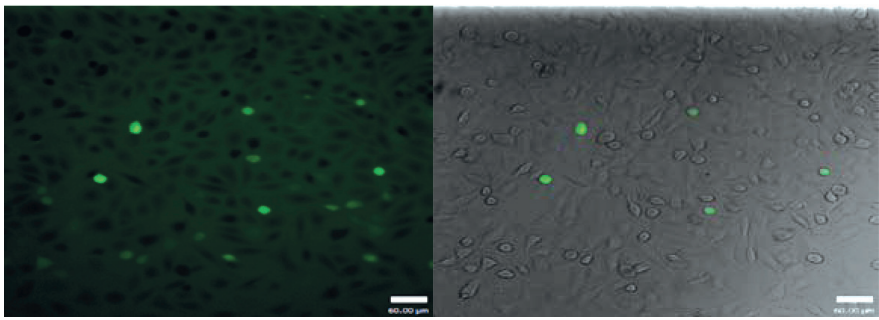

FIGURE 6. The effect of different concentration of EOF on cell viability in HUVEC.

HUVEC were treated with EOF of $30 \mu \mathrm{g} / \mathrm{L}$ (Test1), $300 \mu \mathrm{g} / \mathrm{L}$ (Test 2) and $3000 \mu \mathrm{g} / \mathrm{L}$ (Test 3) for $18 \mathrm{~h}$, followed by TNF- $\alpha$ (10 $\mu \mathrm{g} / \mathrm{L}$ ) stimulation for $6 \mathrm{~h}$. Each photo on the left side was illustrated in GFP detected by Ultra View VOX., and the ones on the right side were with DIC. Vehicle (RPMI-1640) only was control 1 . Vehicle $+\mathrm{TNF}-\alpha(10 \mu \mathrm{g} / \mathrm{L})$ was control 2.

of OF powder increased the expression of SOD in the LPS-induced inflammatory responses.

\section{ROS content and cellular morphology in HUVEC}

The effect of different concentrations of EOF on the ROS contents and growth status of cells were determined morphologically using Ultra View VOX. Each photo on the left side was illustrated in GFP, the ones on the right side were with DIC, from which the growth state of the cells could be clearly seen. The shapes of cells in normal growth state appeared spherical. The cells with a higher ROS contents were demonstrated in green fluorescence with the excitation of moderate laser, and showed irregular or spindle shapes, which suggests the viability of the cells was affected (Figure 6).

The number of cells with irregular or spindle shape in control 2 was more than that in control 1 , which indicated that TNF- $\alpha$ had affected the viability of cells. The number of cells on low viability was less in Test 2 and Test 3 than that in control 2, which indicated that EOF had a protective effect on TNF- $\alpha$ -treated cells. The growth state of cells in Test 1 and control 2 were almost the same, which showed that the EOF at low concentration may not affect the growth state of the cells. The fluorescence intensity of the cells detected under DIC model was consistent with the results shown in Figure 4. 


\section{CONCLUSION}

In conclusion, 3-O-caffeoylquinic acid, caffeic acid 4-O-glucoside, salidroside, 5-O-coumaroylquinic acid, 4-O-coumaroylquinic acid, acteoside, ligustroside, fucosterol, and arjunolic acid were characterized in ethanol-water (70:30, v/v) extracts of EOF. EOF showed strong DPPH and ABTS radicals scavenging activity and reducing power. The content of ROS was significantly inhibited and the activity of SOD was increased by EOF in cytokine-stimulated EC.

\section{ACKNOWLEDGEMENTS}

This research was supported by grants from the Agricultural Technology Extension Foundation of Central Finance [TG (14) 113], the Jiangsu Provincial Agriculture Self-Renovation Foundation [CX (14) 2120], and the Natural Science foundation of Jiangsu Province (BK20141386). It is also supported by China Scholarship Council ([2015/]3012).

\section{CONFLICT OF INTERESTS}

Authors declare no conflict of interests.

\section{REFERENCES}

1. Arfan M., Amin H., Karamać M., Kosińska A., Shahidi F., Wiczkowski W., Amarowicz R., Antioxidant activity of extracts of Mallotus philippinensis fruit and bark. J. Food Lipids, 2007, 14, 280-297.

2. Barnes S., Kirk M., Cowardt L., Isoflavones and their conjugates in soy foods: extraction conditions and analysis by HPLC-ES-MS spectrometry. J. Agric. Food Chem., 1994, 42, 2466-2474.

3. Calhoun D.A., Jones D., Textor S., Goff D.C., Murphy T.P., Toto R.D., et al. Resistant hypertension: diagnosis, evaluation, and treatment. A scientific statement from the American Heart Association Professional Education Committee of the Council for High Blood Pressure Research. Hypertension, 2008, 51, 1403-1419.

4. Clifford M.N., Johnston K.L., Knight S., Kuhnert N., Hierarchical scheme for LC-MS ${ }^{\mathrm{n}}$ identification of chlorogenic acids. J. Agric. Food. Chem., 2003, 51, 2900-2911.

5. de Rijke E., Zappey H., Ariese F., Gooijer C., Brinkman U.A., Liquid chromatography with atmospheric pressure chemical ionization and electrospray ionization mass spectrometry of flavonoids with triple-quadrupole and ion-trap instruments. J. Chromatogr. A, 2003, 984, 45-58.

6. Hatano T., Rei Edamatsu M.H., Akitane Mori HY.F., Yasuhara T., Yoshida T., Okuda T., Effects of the interaction of tannins with co-existing substances. VI.i) Effects of tannins and related polyphenols on superoxide anion radical, and on 1,1-diphenyl-2-picrylhydrazyl. Chem. Pharm. Bull., 1989, 37, 2016-2021.

7. Hung C.Y., Tsai Y.C., Li K.Y., Phenolic antioxidants isolated from the flowers of Osmanthus fragrans. Molecules, 2012, 17, 10724-10737.

8. Huang B., Chen H.Q., Shao, L.Q., The ethanol extract of $O s-$ manthus fragrans attenuates Porphyromonas gingivalis lipopolysaccharide-stimulated inflammatory effect through the nuclear factor erythroid 2-related factor-mediated antioxidant signalling pathway. Arch. Oral. Biol., 2015, 60, 1030-1038.

9. Hwa J.S., Mun L., Kim H.J., Seo H.G., Lee J.H., Kwak J.H., Lee D.U., Chang K.C., Genipin selectively inhibits TNF-alphaactivated VCAM-1 but not ICAM-1 expression by upregulation of PPAR-gamma in human endothelial cells. Korean J. Physiol. Pharmacol., 2011, 15, 157-162.

10. Khan R.A., Khan M.R., Sahreen S., Ahmed M., Assessment of flavonoids contents and in vitro antioxidant activity of Launaea procumbens. Chem. Cent. J., 2012, 6, art. no 43.

11. Kim Y.S., Ahn Y., Hong M.H., Joo S.Y., Jeong M.H., Kim K.H., et al., Carvedilol inhibits expressions of vascular cell adhesion molecule-1, intercellular adhesion molecule-1, monocyte chemoattractant-1, and interleukin-8 via NF- B inhibition in human endothelial cells. Korean Circ. J., 2005, 35, 576-582.

12. Kis E., Rajnai Z., Ioja E., Heredi Szabo K., Nagy T., Mehn D., Krajcsi P., Mouse Bsep ATPase assay: a nonradioactive tool for assessment of the cholestatic potential of drugs. J. Biomol. Screen., 2009, 14, 10-15.

13. Lee D.G., Lee S.M., Bang M.H., Park H.J., Lee T.H., Kim Y.H., Kim J.Y., Baek N.I., Lignans from the flowers of Osmanthus fragrans var. aurantiacus and their inhibition effect on NO production. Arch. Pharm. Res., 2011a, 34, 2029-2035.

14. Lee D.G., Park J.H., Yoo K.H., Chung I.S., Lee Y.H., Lee J.K., Han D.S., Cho S.M., Baek N.I., 24-Ethylcholesta-4,24(28)-dien-3,6-dione from Osmanthus fragrans var. aurantiacus flowers inhibits the growth of human colon cancer cell line, HCT-116. J. Korean Soc. Appl. Bi., 2011b, 54, 206-210.

15. Lee H.H., Lin C.T. Yang L.L., Neuroprotection and free radical scavenging effects of Osmanthus fragrans. J. Biomed. Sci., 2007, 14, 819-827.

16. Lenz T.L., Monaghan M.S., Lifestyle modifications for patients with hypertension. J. Am. Pharm. Assoc., 2008, 48, e92-9; quiz e100-2.

17. Li A.N., Li S., Li H.B., Xu D.P., Xu X.R., Chen F., Total phenolic contents and antioxidant capacities of 51 edible and wild flowers. J. Funct. Foods, 2014, 6, 319-330.

18. Lin L.Z., Harnly J.M., Identification of the phenolic components of chrysanthemum flower (Chrysanthemum morifolium Ramat). Food Chem., 2010, 120, 319-326.

19. Liu J., Nakamura S., Xu B., Matsumoto T., Ohta T., Fujimoto K., Ogawa K., Fukaya M., Miyake S., Yoshikawa M., Matsuda H., Chemical structures of constituents from the flowers of Osmanthus fragrans var. aurantiacus. J. Nat. Med., 2015, 69, 135-141.

20. Ma Y.L., Vedernikova I., Van den Heuvel H., Claeys M., Internal glucose residue loss in protonated $O$-diglycosyl flavonoids upon low-energy collision-induced dissociation. J. Am. Soc. Mass Spectrom., 2000, 11, 136-144.

21. Mertz C., Gancel A.L., Gunata Z., Alter P., Dhuique-Mayer C., Vaillant F., Perez A.M., Ruales J., Brat P., Phenolic compounds, carotenoids and antioxidant activity of three tropical fruits. J. Food Compos. Anal., 2009, 22, 381-387.

22. Omura H., Honda K., HayashI N., Floral scent of Osmanthus fragrans discourages foraging behavior of cabbage butterfly, Pieris rapae. J. Chem. Ecol., 2000, 26, 655-666.

23. Orak H.H., Karamać M., Orak A., Amarowicz R., Antioxidant potential and phenolic compounds of some widely consumed Turkish white bean (Phaseolus vulgaris L.) varieties. Pol. J. Food Nutr. Sci., 2016, 66, 253-260. 
24. Ouyang X.L., Wei L.X., Wang H.S., Pan Y.M.,. Antioxidant activity and phytochemical composition of Osmanthus fragrans' pulps. South Afr. J. Bot., 2015, 98, 162-166.

25. Oyaizu M., Studies on products of browning reactions: antioxidative activities of products of browning reaction prepared from glucosamine. Jap. J. Nut., 1986, 44, 307-315 (in Japanese; English abstract).

26. Re R., Pellegrini N., Proteggente A., Pannala A., Yang M., RiceEvans C., Antioxidant activity applying an improved ABTS radical cation decolorization assay. Free Radic. Biol. Med., 1999, 26 , 1231-1237.

27. Spanos G.A., Wrolstad R.E., Influence of processing and storage on the phenolic composition of Thompson seedless grape juice. J. Agric. Food Chem., 1990, 38, 1565-1571.

28. Tian Q., Li D., Patil B.S., Identification and determination of flavonoids in buckwheat (Fagopyrum esculentum Moench, Polygonaceae) by high-performance liquid chromatography with electrospray ionisation mass spectrometry and photodiode array ultraviolet detection. Phytochem. Anal., 2002, 13, 251-256.

29. Wang L.M., Li M.T., Jin W.W., Li S., Zhang S.Q., Yu L.J., Variations in the components of Osmanthus fragrans Lour. essential oil at different stages of flowering. Food Chem., 2009, 114, 233-236.

30. Weidner S., Amarowicz R., Karamać M., Dąbrowski G., Phenolic acids in caryopses of two cultivars of wheat, rye and triticale that display different resistance to pre-harvest sprouting. Eur. Food Res. Technol., 1999, 210, 109-113.
31. Wu L.C., Chang L.H., Chen S.H., Fan N.C., Ho J.A.A., Antioxidant activity and melanogenesis inhibitory effect of the acetonic extract of Osmanthus fragrans: A potential natural and functional food flavor additive. LWT - Food Sci. and Technol., 2009, 42, 1513-1519.

32. Yin W., Liu J.Q., Zhang G.S., Chemical constituents of Osmanthus fragrans fruits. Zhongguo Zhong Yao Za Zhi, 2013, 38, 4329-4334 (in Chinese; English abstract).

33. Xiong L., Yang J., Jiang Y., Lu B., Hu Y., Zhou F., Mao S., Shen C., Phenolic compounds and antioxidant capacities of 10 common edible flowers from China. J. Food Sci., 2014, 79, C517-C525.

34. Yoo K.H., Park J.H., Lee D.K., Fu Y.Y., Baek N.I., Chung I.S., Pomolic acid induces apoptosis in SK-OV-3 human ovarian adenocarcinoma cells through the mitochondrial-mediated intrinsic and death receptor-induced extrinsic pathways. Oncol. Lett., 2013, 5, 386-390.

35. Zeng Y., Deng M., Lv Z., Peng Y., Evaluation of antioxidant activities of extracts from 19 Chinese edible flowers. SpringerPlus, 2014, 3, 315 .

Submitted: 29 January 2016. Revised: 11 August, 1 October and 28 November 2016. Accepted: 7 December 2016. Published on-line: 21 April 2017. 
